\title{
O desafio das competências no serviço público: contribuições teóricas
}

\section{El desafío de las competencias en el servicio público: contribuiciones teóricas}

\section{The challenge of competences in the public service: theoretical contributions}

\author{
Claudete Francisco de Sousa* \\ Universidade Federal Fluminense - UFF, Niterói, Rio de Janeiro, Brasil
}

\section{Hélder Pordeus Muniz**}

Universidade Federal Fluminense - UFF, Niterói, Rio de Janeiro, Brasil

\begin{abstract}
RESUMO
Este artigo propõe uma discussão teórica sobre competências no serviço público a partir da perspectiva ergológica e segundo a contribuição sociológica de Zarifian. A ergologia enfatiza a importância de se criticar a simplificação das mensurações das competências sugerindo uma abordagem do agir em competência com base em ingredientes. Zarifian apresenta 0 conceito de relação de serviço entendido como uma transformação nas condições de atividade do usuário mediante suas necessidades. Ambas as abordagens envolvem a necessidade de uma gestão de competências centrada no ponto de vista da atividade e fazem a crítica de um gerenciamento que exclua os trabalhadores das decisões sobre o seu trabalho.
\end{abstract}

Palavras-chave: competências, trabalho, atividade, serviço público.

\section{RESUMEN}

Este artículo propone una discusión teórica sobre las competencias en el servicio público en la perspectiva ergológica y segundo la contribuición sociológica de Philippe Zarifian. La ergología enfatiza la importancia de criticar la simplificación de las mediciones de las competencias sugiriendo un enfoque de actuar en competencia por medio de los ingredientes. Zarifian presenta el concepto de la relación de servicio que se entiende como un cambio en las condiciones de la actividad del usuario por medio de sus necesidades. Ambos los enfoques envolven la necesidad de una gestión de competencias centrada en el punto de vista de la actividad y hacen la crítica de una gerencia que excluya a los trabajadores en las decisiones sobre su trabajo.

Palabras-clave: competências, trabajo, actividad, servicio público.

\section{ABSTRACT}

This article proposes a theoretical discussion on competences in the public service based on the ergological perspective and according to Zarifian's 
sociological contribution. Ergology emphasizes the importance of criticizing the simplification of the measurement of competences, by suggesting an approach to acting in competence that is based on ingredients. Zarifian introduces the concept of service relationship, which is understood as a transformation in the conditions of a user's activity upon his needs. Both approaches imply the need for a competence management centered on the point of view of activity and are critical of a management that excludes workers from decisions about their work.

Keywords: competences, work, activity, public service.

\section{Introdução}

O debate sobre as competências para o trabalho ganha destaque nos dias atuais, pois vivenciamos um momento da História em que se apresenta um discurso sobre a necessidade de trabalhadores cada vez mais capacitados a fim de dar conta das exigências do mercado. O setor público, mesmo tendo natureza e objetivos diversos do setor privado (pequenas, médias e grandes empresas), adotou essa premissa apostando que para o país alcançar melhorias é crucial voltar o olhar para o servidor investindo em sua capacitação para os desafios contemporâneos (Amaral, 2006). Esse tem sido um desafio para os psicólogos do trabalho que atuam nos serviços públicos.

Assim, no ano de 2006, por meio do decreto presidencial n. 5.707 (Brasil, 2006), é implementada a gestão por competências no serviço público federal brasileiro. O decreto, que dispõe sobre a Política e as Diretrizes para o Desenvolvimento de Pessoal da administração pública federal direta, autárquica e fundacional, preconiza que a gestão por competências deverá ser adotada como a política de "recursos humanos" em todos os órgãos da esfera pública federal brasileira.

Seguindo essa diretriz, em 2009 o então ministro do Planejamento, Orçamento e Gestão, Paulo Bernardo Silva, afirmou que o crescimento que o governo Lula havia almejado e estava alcançando pressupunha servidores aptos para lidar com novas questões que antes não eram apresentadas. De acordo com o ministro, "novos tempos pressupunham novos desafios e, portanto, novas competências, e para isso nós deveríamos estar preparados" (Brasil, 2009, p. 17).

Todas as organizações do serviço público tiveram que se adaptar de forma acelerada a essa nova política, a qual trazia desafios e questionamentos para os profissionais - incluindo os psicólogos que atuam mais diretamente na "gestão de pessoas" ${ }^{1}$ das universidades públicas.

O que eram as competências? O que seria na prática uma gestão por competências? Seria algo possível no serviço público, ou algo adequado apenas para empresas privadas? As dúvidas surgidas no 
processo de implementação dessa política foram o incentivo para que uma profissional desse campo procurasse realizar um mestrado a fim de pesquisar a temática. Assim, com a supervisão de seu professor orientador - e em parceria com ele, que já pesquisava a gestão e o gerenciamento do trabalho nos serviços públicos do ponto de vista da atividade -, realizou uma pesquisa em que se observou o crescente interesse acadêmico-científico sobre o tema das competências e do gerenciamento no serviço público.

Os trabalhos de Muniz (2000), Gomes e Araújo (2009), Souza (2009), Nogueira (2012), Silva-Roosli (2012), Souza e Christo (2015) exemplificam esse crescimento e apontam para a riqueza de uma abordagem da competência na perspectiva ergológica, que considera o ponto de vista da atividade dos trabalhadores e alerta para os riscos de um gerenciamento que o ignore.

Este artigo, de autoria da referida psicóloga e de seu orientador de mestrado, visa discutir teoricamente o tema das competências no serviço público como contribuição para o campo da psicologia do trabalho e organizacional, que necessita desenvolver seus instrumentos teóricos e metodológicos - como alertam as pesquisas de Borges (2006) e Rezende (2014). Contudo, consideramos que, para discutir as competências ou a gestão por competências, 0 sentido a ser dado para a expressão "trabalho" tem grande relevância - e a esse respeito pontuamos que, neste estudo, adotamos como perspectiva a ergologia.

Entendida como uma postura ético-epistemológica, a ergologia tem Yves Schwartz como principal expoente e nos dá algumas pistas de que, para propormos um debate fecundo sobre as competências, será necessário ir além daquilo que está dado. Ou seja, será necessário afirmar que trabalhar é sempre estar em um constante debate de normas num mundo de valores, pois o trabalho não é apenas prescrição ou realização de tarefas. Ao contrário, para realizá-lo, o trabalhador estará sempre renormatizando seu meio de trabalho (Schwartz, 2011), em virtude das variabilidades que ocorrem e são inerentes ao vivente. Para tal, ele se engaja por inteiro, com seu corpo biológico, sua inteligência, seu psiquismo e os conhecimentos apreendidos no decorrer de sua história e nas relações com os outros (Telles \& Alvarez, 2004).

Dito de outro modo, o trabalhador faz um uso de si por outros e um

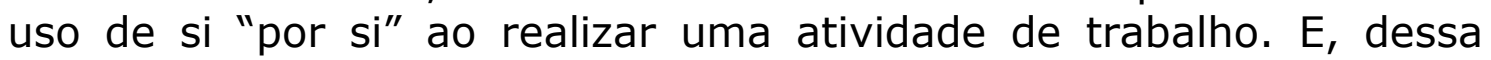
forma, falar de uso de si remete ao fato de que os trabalhadores não executam apenas tarefas manuais ou intelectuais, pois, fazem uso de suas capacidades e recursos que envolvem um todo que não é separado em corpo e mente. Por outro lado, o uso de si por outros diz respeito ao fato de que todo trabalho é em parte heterodeterminado e que o uso de si que cada trabalhador faz não é jamais fruto apenas de sua individualidade, porque os outros estarão 
lá - por meio do planejamento do trabalho, da prescrição, da avaliação, dos protocolos, das normas antecedentes e também dos valores coletivos. Porém, como há variabilidade e necessidade de renormatização os trabalhadores também fazem uso de si por si, criando suas próprias normas para dar conta da complexidade e das infidelidades que se apresentam no meio. Assim, o encontro do ser humano com o trabalho é rico, porque a atividade nunca será pura execução e porque sempre existirão as variabilidades e infidelidades do meio (Canguilhem, 2010) ${ }^{2}$, que convocarão o ser humano a um constante debate de normas e valores e a um drama a se viver.

Acrescentaremos a essas reflexões as contribuições de Philippe Zarifian (2001a, 2001b, 2001c), autor que aborda a lógica e a relação de serviço, conceitos caros para o serviço público e que articulados com a ideia apresentada por Yves Schwartz - sobre a dimensão dos valores do bem comum e dos valores mercantis - contribuem para a reflexão de que o serviço público comporta uma dimensão constituída por critérios e valores diferentes daquela que estrutura o mercado. Assim, a relação que o trabalhador estabelece no primeiro contexto é orientada de maneira diversa da relação do trabalhador que está no setor privado. Ou seja, os valores que norteiam e direcionam o trabalhador inserido no serviço público se constituem pela chamada lógica do bem comum, que é diferente da lógica do mercado, dimensão que no contemporâneo direciona os debates sobre as competências.

\section{O conceito de atividade de trabalho e suas contribuições para o debate das competências}

O conceito de atividade de trabalho - compreendido pela ergologia como uma das dimensões da atividade humana - ainda está em definição e se configura na maneira pela qual as pessoas se engajam na gestão dos objetivos do trabalho, num lugar e num tempo determinados, servindo-se dos meios disponíveis ou inventando outros meios (Telles \& Alvarez, 2004).

Guérin, Laville, Daniellou, Duraffourg e Kerguelen (2001), por sua vez, observam que a atividade de trabalho, além de ser o elemento central que organiza e estrutura os componentes da situação de trabalho, unifica tal situação, pondo em ação e organizando as suas dimensões técnicas, econômicas e sociais. Assim, a atividade não pode ser reduzida a uma prescrição de tarefas, e o trabalho torna-se "tomada de iniciativa para fazer o sistema funcionar", compreendendo a gestão de acasos de toda ordem, a antecipação, a gestão simultânea de vários horizontes temporais e ainda, ao mesmo tempo, compreendendo atividade individual singular e atividade coletiva (Rouilleault, 2001). 
Desse modo, no debate sobre as competências - apesar da tendência atual, conforme observa Durrive (2010), que consiste de certo modo em listar exaustivamente as competências, supondo que a experiência poderia estar inteiramente contida nas palavras - cabe ressaltar que a atividade pode envolver uma parte do trabalho que não é rotineira, e só acontece uma vez ou outra. Por isso, quando as situações inesperadas e os eventos acontecem, o trabalhador pode não refletir sobre suas ações, existindo assim dimensões da atividade de trabalho de que o próprio trabalhador não toma consciência.

A aposta a ser feita para tentar acessar parcialmente o que seria da ordem do não dito, do inconsciente e do enigmático da atividade, é estar com o trabalhador para propor um dispositivo em que este verbalize e explique para os colegas, para nós e para si mesmo parte das exigências e estratégias de sua atividade, compreendendo que somente no contato com o próprio trabalhador poderemos nos inteirar minimamente do modo que ele trabalha, e também dos meios de que dispõe para fazê-lo. Porém, o fundamental é que ao dialogar com o trabalhador sobre sua atividade, o mesmo se apropria de maneira diferente de suas competências, podendo fazer uma avaliação crítica das mesmas, o que produz um desenvolvimento de sua experiência.

Ressaltamos por esse motivo, que a Ergologia privilegia a atividade de trabalho, tendo por premissa que, para se falar desta, é necessário conhecê-la de perto a fim de que seja constituído o ponto de vista da atividade, levando em conta que será importante colocálo em diálogo com outros pontos de vistas presentes em uma dada situação de trabalho (Schwartz \& Durrive, 2010).

É importante esclarecer que falar do ponto de vista da atividade não é falar do "ponto de vista do trabalhador", e, de sua opinião. Inicialmente esta pode ser a ideia obtida, contudo, atingir o ponto de vista da atividade é difícil, pois ele comporta uma parte do trabalho e do que o trabalhador mobiliza para executá-lo, que nem sempre se tem consciência. Ou seja, a atividade pode envolver uma parte do trabalho que não é rotineira, e que só acontece uma vez ou outra, e quando as situações inesperadas e os eventos acontecem, 0 trabalhador pode não refletir sobre suas ações, o que resultará em dimensões da atividade de trabalho que este trabalhador não tomará consciência ${ }^{3}$.

Por esse motivo, para a ergologia a noção de competências está diretamente relacionada à noção de atividade. Pois como pensar em competências para um trabalhador se, para cada situação, tudo varia e se transforma?

Estamos atentos para o alerta de Schwartz (2010a), quando este autor observa que se desejarmos pôr em palavras - ou se nos impusermos a obrigação de colocar em palavras - tudo aquilo que sabemos fazer, isso reduziria a riqueza que está presente em todas 
as atividades. Desse modo, é preciso sempre considerar que "aquele que age, aquele que trabalha", fará em todo momento uso de numerosos recursos que, ao serem nomeados ou classificados, tenderão a comprometer a riqueza dos elementos presentes em uma situação de trabalho.

\section{O uso de si "por si", o uso de si "por outros" e o "corpo-si": tríade imprescindível no debate das competências}

O trabalho é infinitamente mais complicado do que podemos imaginar - e ainda que não tenhamos clareza, o fato é que uma atividade de trabalho, mesmo aquela que à primeira vista seria repetitiva, tende a variar, pois nada é idêntico. Todo gesto, toda atitude, por mais simples que seja, é carregado de sensibilidade, estratégia, inteligência e todo um saber-fazer que é subestimado (Duraffourg, 2010). Assim, é importante reconhecer-se a riqueza presente no agir em uma situação de trabalho que será sempre única, pois nunca se repetirá, e também porque o trabalhador fará uso de suas vivências, de sua experiência, de sua singularidade, além do uso de si por si e do uso de si por outros.

Retomando o que foi apontado na introdução deste texto, observamos que, para realizar uma atividade de trabalho, o ser humano será regido pelo uso de si por si e também pelo uso de si por outros. O primeiro é caracterizado pelo uso que uma pessoa faz de seu próprio corpo, de sua inteligência, de sua história, de sua sensibilidade e de seus gostos; e o segundo, que denota a dimensão social do trabalho, diz respeito, conforme observam Nascimento e Muniz (2016), ao fato de que em toda atividade estarão presentes normas provenientes do outro, sejam técnicas, sejam de relações de poder - havendo a todo instante uma ressingularização em razão de elementos novos conquistados a partir dessa renormatização com valores coletivos.

Porém, o uso de si por si, o qual também é atravessado pelo uso de si por outros, comporta a ideia de que há sempre um destino a se viver, com escolhas que somente quem trabalha deverá fazer para dar conta de sua tarefa. E nesse processo, com base em tais escolhas, o trabalhador é remetido aos seus dramas mais profundos. Ainda assim, a dimensão do drama presente no encontro do ser humano com o seu trabalho acontece, pois sempre ocorre algo no trabalho, e isso não quer dizer necessariamente uma história triste. De acordo com Schwartz e Mencacci (2008), etimologicamente "dramática" quer dizer que há uma história, ou seja, que se passa uma história que não foi prevista antecipadamente, e que não é necessariamente trágica. O ser humano irá se deparar sempre com um debate no qual não poderá escapar, e esse é um "destino a 
viver". Podemos lembrar, por exemplo, que as obras dos dramaturgos envolvem tragédias e comédias e o que há de comum em ambas é um elemento conflitual dinâmico que movimenta a história. A esse respeito, Durrive (2010) diz que trabalhar, de alguma forma, seria colocar à prova do real seus próprios limites e suas próprias capacidades, correndo riscos e estando em situação de teste todo o tempo. Posto isso, a expressão dramática de uso de si significaria recolocar algo de drama, no sentido de uma grandeza, naquilo considerado infinitamente pequeno ou negligenciável. Seria "tudo aquilo que é a confrontação em um momento particular, na qual o trabalhador tenta encontrar uma solução para um problema que se apresenta com toda a sua história" (Schwartz, 2010b, p. 89).

Chamando para esse diálogo Zarifian (2001b), vimos que, para ele, o "trabalho" é a ação competente do indivíduo diante de uma situação de evento, e o "trabalhar" seria estar atento (expectação) a tais eventos, pressentindo-os e enfrentando-os quando estes se apresentam. O evento definido então como aquilo que ocorre de maneira parcialmente imprevista seria parte do cotidiano de uma organização, e em torno do qual se dariam as intervenções humanas mais complexas.

Essa ideia nos remete de pronto ao que dispõe Schwartz (2010b) sobre o fato de o trabalhador, em uma situação de trabalho, sempre se deparar com as infidelidades do meio - isto é, com os imprevistos e variabilidades, de que dará conta por meio do uso de si "por si" e do uso de si "por outros". Caberá ao próprio trabalhador encontrar as respostas a serem dadas a um determinado ambiente social complexo e instável, já que o trabalho nunca será pura execução. E a gestão dessas infidelidades acontecerá mediante as próprias normas e escolhas do trabalhador, que ao tentar recentrar o meio o singulariza, dando a ele a conformação necessária.

No entanto, que entidade é essa a que temos nos referido com toda a sua singularidade? Neste texto, ora falamos de trabalhador, ora falamos de homem; porém, o que isso comporta para a ergologia?

Para responder a estas perguntas, vimos que Schwartz (2010c), contrariando a ideia de uma oposição entre "corpo" e "alma", utiliza o conceito de "corpo-si", partindo do pressuposto de que não se trata apenas de um corpo biológico, já que existe uma pessoa com sua singularidade e história de vida. O corpo-si seria aquilo que há de enigmático e não se pode objetivar e apreender nem na clara consciência, nem nos debates subjetivos comumente ouvidos. Para o autor, não seria possível descartar esse corpo, que não é nem inteiramente biológico, nem inteiramente consciente ou cultural, pois por meio dele seriam arbitradas e geridas as variabilidades permanentes e as dramáticas com as quais o ser humano se depara. Essa gestão se daria com base nas economias corporais, nas sinalizações sensoriais e na própria inteligência do corpo. 
O corpo-si se apresenta então como uma entidade não inteiramente biológica, nem inteiramente cultural ou histórica, que ultrapassa a ideia de um eu privatizado. E justamente em razão de tais questões é um corpo que não se opõe à alma, como na filosofia clássica. É a entidade responsável por conjugar aquilo que é tanto fisiológico quanto o que é cultural e histórico, passando pelo psíquico, pelos valores, enfim, dando conta do que torna um vivente singular (Schwartz, 2010c).

Mesmo afirmando não existir limiar na noção de corpo-si, Schwartz (2010c) propõe três dimensões que o "si" acumularia e às quais o menor ato de trabalho seria remetido:

a primeira é que existe um nível do si que é o corpo inserido na vida, o corpo a partir do fato de que somos parte do mundo da vida, sendo o si inseparável do movimento de evolução da vida;

a segunda dimensão aponta que o si está, desde o nascimento, em um universo de cultura, atravessado e saturado de valores, histórias, conflitos e normas antagônicas;

já a terceira dimensão afirma que o si é também história psíquica, uma dramática, já que o ser humano está inserido em um contexto social regido por normas e leis com as quais seu desejo se defronta.

Schwartz (2014) vai então preferir deixar de utilizar o conceito de dramáticas de uso de si por si e uso de si por outros, substituindo pelas dramáticas de uso do corpo-si, deixando mais evidente esta sua concepção de uma dimensão subjetiva do trabalho que não é separada da vida e dos valores que a afirmam.

Assinalamos, considerando o tema central deste texto - o debate sobre as competências circunscrito ao contexto do serviço público -, que todo trabalhador, ao lançar mão desse corpo si, vai se deparar com uma situação de trabalho que é impossível de ser estandardizada, pois a atividade é vida, e a vida não acontece sob o registro do enquadramento (Schwartz, 2010c). Por isso torna-se difícil delimitar, definir, catalogar e avaliar exatamente o que poderiam ser as competências.

Ao incluir mais um aspecto nesse debate, concordamos com o entendimento de Nogueira (2012), tendo em mente que, ao imprimir o olhar ergológico sobre a questão das competências, é importante compreender que, para desenvolvê-las, será necessário certo tempo, e que não se deve considerá-las somente com base no polo mercantil, que pretensamente tenta decompor as competências em itens definíveis. Mas o que isso significa?

Podemos afirmar, segundo o paradigma ergológico, que mesmo na vida cotidiana as competências estão e sempre estiveram presentes, 
sendo necessário se considerarem as competências para viver, para comer, para se deslocar e para estabelecer relações com os nossos semelhantes. De tal modo que tudo isso existe também no trabalho, ou seja, tudo isso está profundamente reinvestido, e por esse motivo seria algo de totalmente ilusório pensar em elaborar uma lista exaustiva de competências.

Revela-se completamente ilusório o tipo de cuidado metodológico, de ferramentas de direção, que consiste em pensar poder pôr em palavras, em séries, todos os conteúdos de uma competência. Não que não haja neste sentido uma dimensão justa, positiva, mas há também uma dimensão ilusória, como se fosse possível detalhar a lista das competências necessárias para viver (Schwartz, 2010d, p. 141).

O autor ainda nos alerta para o fato de que as competências para viver - ou as competências em geral - não são somente a capacidade para fazer isso. A discussão deveria se concentrar no reconhecimento de que o trabalhador é permanentemente uma "pessoa" envolvida indefinidamente em circunstâncias sempre variáveis a que a história o submete, com colegas diferentes uns dos outros e que se modificam, com desafios delicados, valores que se contradizem e cujo resultado nunca é predeterminado.

Ao contrário, o que acontece hoje é que ao afirmarmos que "uma pessoa é competente para isso" pretendemos, de algum modo, encerrá-la em uma dada situação, uma vez que ao "reconhecermos" a capacidade dela para "isso" ou "aquilo" estamos realizando o aprisionamento da pessoa em tal reconhecimento. Ou seja, ocorre uma limitação "da capacidade indefinida dessa pessoa para fazer novas arbitragens e, de certo modo, para recompor mais ou menos seu meio de trabalho (Schwartz, 2010d, p. 142)".

Para sair de tal paradoxo, apesar de dizer que é difícil chegar a uma definição relativamente operacional das competências, Schwartz (2010d) aborda a questão por meio da metáfora de uma boa culinária e mostra que, da mesma forma que para se alcançar o bom resultado em uma mistura é necessária a combinação de diversos ingredientes, cada qual com sua medida. Para um "agir competente" também seria preciso a utilização de ingredientes, de elementos heterogêneos que, articulados, comporiam o perfil de uma pessoa para um "agir competente" numa determinada situação de trabalho.

Nesse sentido, o primeiro ingrediente está relacionado ao domínio dos protocolos e procedimentos do trabalhador para cumprir determinada tarefa, ou seja, refere-se à capacidade do ser humano para dominar os saberes científicos, técnicos, de ordem econômica, 
gestionária, jurídica, de códigos, linguagem etc. que constituem determinada situação.

Acerca desse primeiro ingrediente, fazemos uma correlação com o momento do ingresso do trabalhador no serviço público, quando caberá a ele não apenas se apropriar das normas e regras que nortearão sua atividade, mas também se apropriar de todo conhecimento que tenha relação com suas atividades.

O segundo ingrediente difere do primeiro, pois faz menção à capacidade do ser humano de incorporar o histórico de uma situação de trabalho, de se deixar impregnar pela dimensão singular da situação de trabalho. É relativo à capacidade do ser humano para enfrentar 0 meio no qual se encontra, submetido a incessantes transformações, por um lado não antecipáveis. Entendemos que possuindo esse ingrediente o trabalhador estará sensível aos estímulos que receber e atento no sentido de que cada situação será sempre uma situação singular que carecerá de respostas que também escapem das generalizações. Assim, grande parte das competências necessárias surge no próprio trabalhar, e não antes dele.

O terceiro ingrediente está relacionado à capacidade do ser humano de articular a dimensão dos protocolos e procedimentos (ingrediente 1) à dimensão singular de cada situação de trabalho (ingrediente 2). Dito de outra forma: é quando o trabalhador consegue pôr em diálogo e articular os conhecimentos que possui em determinada situação.

Para a realização de determinada atividade é imprescindível que o trabalhador, ao executá-la, articule o conhecimento que tem acerca de normas, regras e procedimentos à situação que a ele se apresenta. Em nossa experiência de trabalho, por exemplo, levando em conta a natureza de nosso serviço - que é principalmente atender e acompanhar servidores que venham apresentar quaisquer dificuldades que interfiram negativamente em sua vida funcional nossa prática a todo momento precisa se valer de normas institucionais. Entretanto, ao agirmos, precisamos encontrar a "medida certa" no trato daquele que nos procura, daquele que muitas vezes encontra-se em sofrimento por motivos diversos e que necessariamente precisará ser acolhido em sua singularidade e também na singularidade de sua situação. ${ }^{4}$

$O$ ingrediente quatro está ligado ao debate de normas que cada um vive em seu meio de trabalho. Os valores que perpassarem a situação de trabalho colocam o trabalhador diante de uma dramática, e ao fazer um uso de si e também havendo um uso de si pelos outros, esse trabalhador precisará fazer com que o meio de trabalho seja em parte seu. Assim, as soluções encontradas para os problemas terão relação direta com a implicação desse trabalhador em seu dia a dia de trabalho. 
Em nossa prática profissional na universidade, a todo momento somos convocados a um debate de normas num mundo de valores levando em conta que nosso público-alvo são servidores com dificuldades de natureza diversa, em seus locais de trabalho. É recorrente, inclusive, lidarmos com o posicionamento de gerentes que vão de encontro a uma política de gestão que considere de fato aquele que trabalha. O resultado de tal situação é que somos confrontados com um drama que exigirá de cada um de nós um "uso de si" por si e também um "uso de si por outros", a fim de encontrarmos uma solução a mais acertada possível tanto para o servidor como para a universidade. Muniz (2000) afirma que esse quarto ingrediente envolve diretamente a importância das políticas de gerenciamento das situações de trabalho que podem auxiliar a desenvolver valores de solidariedade, de bem comum, ou individualismos e competições que tendem a produzir desmobilização subjetiva dos trabalhadores.

O quinto ingrediente de uma competência é a ativação ou a duplicação do potencial da pessoa, com suas incidências sobre cada ingrediente. Se expressa quando um meio, ao ter valor para o trabalhador, viabiliza que todos os ingredientes da competência sejam potencializados e desenvolvidos. É a mobilização do potencial do trabalhador que se apresenta na realização de uma tarefa por inteiro. Compreendemos que a presença desse ingrediente se expressa diante de todos os desafios que nos sobrevêm. Quando, por exemplo, somos confrontados com um debate de normas e valores acerca de decisões que deverão ser tomadas, de encaminhamentos que deverão ser dados, buscamos fazê-lo sempre da maneira mais cuidadosa possível, levando em conta as normas e os procedimentos que precisamos respeitar, mas também a singularidade de cada situação. Arriscamos dizer que esse ingrediente se expressa ainda ao termos uma prática permanente de colocar em análise as decisões tomadas, os encaminhamentos realizados e, principalmente, quando problematizamos nossas condutas e nossas posturas diante de determinada situação - visto sermos um corpo-si que se apropria e faz parte de um dado contexto e busca inclusive intervir nesse meio para que este tenha algo de seu, de sua marca, de sua singularidade. Para finalizar, o sexto ingrediente de uma competência é saber tirar partido das sinergias de competências em situação de trabalho. Está relacionado à capacidade do ser humano de reconhecer e respeitar a diversidade existente entre as pessoas, com o entendimento de que o trabalho coletivo supõe pôr em sinergia os diferentes ingredientes não em si mesmo, mas coletivamente. Representa a origem e o resultado das interações realizadas, das sinergias coletivas e da ligação com os outros. Tal ligação é que daria um sentido global ao agir individual. Seria a capacidade do coletivo de se coordenar, de produzir um debate de normas e valores fazendo uso das diferenças 
presentes no meio, com a clareza de que o trabalho nunca será um ato individual, mas sempre coletivo.

Os seis ingredientes listados, de acordo com Schwartz (2010d), comporiam as competências da atividade industriosa - ou seja, da atividade de trabalho - que, em razão de suas especificidades, não poderiam ser avaliadas, mensuradas ou dimensionadas do mesmo modo e por meio dos mesmos instrumentos. Tais ingredientes apontariam para aprendizagens múltiplas originadas na experiência de trabalho e se manifestariam na forma da capacidade e habilidade do trabalhador ao se defrontar com uma situação-problema. Esses ingredientes tenderiam a interagir dinamicamente ante os desafios, no instante em que as competências fossem requisitadas.

A metáfora realizada por Yves Schwartz com a noção de ingrediente facilita o debate sobre o tema. Nesse ponto, arriscamos dizer que mesmo não sendo possível, conforme já visto, listar as competências necessárias a um trabalhador em determinada situação de trabalho, torna-se plausível uma reflexão sobre o modus operandi que esse trabalhador deverá adotar para a consecução de dada tarefa e consequentemente de sua atividade.

Com base nos ingredientes listados por Schwartz (1998, 2010d), fomos remetidos ao modo como cada trabalhador se coloca diante de uma situação de trabalho, e essa discussão no debate das competências torna-se possível. Entretanto, será imprescindível não alijar o trabalhador desse processo. Ou seja, ao se refletir sobre o que comporta uma atividade de trabalho e principalmente o que ela convoca naquele que age, será imprescindível fazê-lo junto àquele que trabalha. A compreensão que precisamos ter é que para esse exercício não há expert mais indicado que o próprio trabalhador, pois é ele que no dia a dia irá se deparar com as numerosas variabilidades e infidelidades do meio, dando conta de cada uma delas a fim de alcançar a conformação necessária.

Porém, é muito importante saber que as competências envolvem saberes, mas também um trabalho com os valores. Essa não é uma discussão apenas técnica, porque implica escolhas de um projeto de serviço, bem como de um modo de se viver junto (Schwartz, 2010e).

\section{O conceito de relação de serviço ante os valores do bem comum e os valores mercantis}

Ao pensarmos nas histórias da vida, do ser humano e de uma sociedade com todas as suas facetas, é preciso considerar que ela se faz e acontece com a existência de três polos. Segundo Schwartz (2010e), um deles pode ser chamado de polo "orientado por valores mercantis", ou seja, pelos valores do mercado, que têm grande impacto em nosso quotidiano, em nossa vida, nas esferas social, 
política e cultural. É o polo dos valores dimensionáveis, em que predomina a lógica de que tudo se orienta em função de valores quantificáveis. Assim, as unidades de medidas são utilizadas para qualquer fato, se assim for conveniente.

O outro polo é onde estão em jogo apostas, os valores que não se mensuram em quantidades em virtude de sua natureza, já que fazem referência ao bem-estar de uma população. É onde se encontram questões como: o que é a saúde? Como preparar um planeta vivível para todos nas gerações futuras? O que é cultura? O que é satisfação e prazer para as pessoas? Ou seja, é um polo constituído por valores referentes ao bem viver em comum e que se espera ou reivindica serem assumidos pelas instituições de cunho político, dentre elas o Estado. Nomeia-se também como o polo do político, do direito, das ações políticas e dos valores não dimensionados. ${ }^{5}$

Deve-se observar que esses polos interagem, mesmo sendo orientados por lógicas diferentes. Segundo Schwartz (2010e), o polo do político não necessita submeter-se às exigências do polo mercantil, porém, ao mesmo tempo, produz um efeito sobre este polo para que se assegure um retorno positivo para os cidadãos que ele tem sob sua égide. O polo mercantil, por sua vez, não pode unicamente se afirmar impondo uma onipresença e a hegemonia de seus valores quantitativos e mercantis.

Tal processo seria estruturado dessa maneira pela inclusão de mais um polo, definido como o polo das "dramáticas do uso de si", dos debates de normas, das gestões, ou como o polo da atividade humana, polo em que o ser humano teria lugar de destaque. $O$ que ocorre é que segundo essa configuração os seres humanos, ao colocarem a engrenagem da vida (em nível social, financeiro e do próprio trabalho) para funcionar, seriam orientados pela ética, pelo uso de si "por si" e pelo uso de si "pelos outros", a fim de dar conta das dramáticas oriundas da interação entre os citados polos. Isso significa dizer, por exemplo, que o polo do mercado, ao confrontar-se com o polo do político, teria sempre, neste último, uma ancoragem no polo da gestão das dramáticas do uso de si, em seu nível mais individual, diretamente ou por intermédio das leis e políticas públicas. Assim, a história não seria feita, jamais, sem incorporar essas dramáticas de uso de si que estão relacionadas desde o mais global até o mais individual.

Ao tomarmos essas reflexões como diretriz, observamos que no contemporâneo existe uma série de práticas, dentre elas as políticas de gestão por competências, que apontam em geral para o polo mercantil. Ao se considerar que, a princípio, o serviço público é orientado pela lógica dos valores sem dimensão, seria correto afirmar que a incorporação de tais políticas pelos órgãos de governo caracterizaria uma imersão destes na dimensão dos valores quantificáveis? 
O que defendemos neste estudo é que o debate deve priorizar a maneira como tais processos são implementados e não adotar uma postura que demonize a discussão, com o argumento de que por serem políticas oriundas da esfera privada seriam inadequadas ao serviço público. Entendemos ainda a importância de uma reflexão sobre a relação de serviço que qualifica a prestação de um serviço público articulada com uma reflexão sobre a relação que o próprio trabalhador estabelece com a sua atividade nesse contexto.

Zarifian (2001a, 2001b, 2001c, 2003) nos auxilia nesse exercício, ao explicitar seu entendimento sobre o conceito de relação de serviço e o enquadre teórico que o norteia. Vimos que a definição de serviço é apresentada por meio de uma dupla abordagem, que leva em conta as consequências e os efeitos do serviço e também os recursos utilizados pelo trabalhador, em que:

o serviço seria uma transformação nas condições de atividade do destinatário, cujas consequências são consideradas válidas e positivas por este último e pela coletividade;

o serviço seria a organização e a mobilização, o mais eficiente possível, de recursos, visando interpretar, compreender e produzir a citada transformação.

Dito de outra maneira, serviço seria "uma organização e uma mobilização, o mais eficiente possível, de recursos para interpretar, compreender e gerar a mudança perseguida nas condições de atividade do destinatário do serviço" (Zarifian, 2001c, p. 119).

Juntamente com essa definição, é preciso compreender algumas ideias que a contornam. A primeira delas é que, segundo Zarifian (2001a), há evoluções convergentes entre o chamado setor industrial e o setor de serviços, pois o setor industrial descobriu e incorporou conceito de "serviço". Entretanto, o setor dos serviços industrializou seus modos de funcionamento e, ao fazê-lo, passou a incorporar em sua produção, em sua tecnologia, em sua organização social, em seus objetivos de eficiência, princípios semelhantes aos desenvolvidos na indústria. Ou seja, passou a se utilizar de valores oriundos do polo mercantil.

Compreendemos que tal transformação também se dá no setor de prestação do serviço público brasileiro, sendo necessário, dessa maneira, nos ater ao conceito de "lógica de serviço" (Zarifian, 2001a) surgido na França. A ideia principal que a embasa é de que o serviço não é somente o ponto de chegada da produção, mas é também o ponto de partida, o que justificaria sua existência e permitiria avaliar a performance de uma organização. Ao se falar em "missão de serviço público", esta precisaria ser entendida como a finalidade a orientar toda a organização de um órgão, sobre a qual deveriam ser 
parcialmente julgados os resultados a serem alcançados (Zarifian, 2001a).

Nesse sentido, algumas questões sobrevêm, dentre elas: como os trabalhadores, servidores públicos, constroem o sentido do seu trabalho? Quais valores o referenciam? Seriam valores do bem comum ou mercantis? E ainda: será que todo o trabalhador que ingressa no serviço público considera a importância de trabalhar para atender às necessidades de uma população?

Mesmo sem nos ater a responder a tais questões, chamamos a atenção para o fato de que independentemente do contexto, público ou privado, o debate sobre as competências pressupõe a prestação de um serviço com qualidade, eficácia e eficiência - por isso torna-se imprescindível uma construção e apropriação por parte dos trabalhadores do sentido que comporta produzir um serviço público.

Por esse motivo, apostamos que toda e qualquer iniciativa incluída em uma política de gestão de pessoas seja realizada com a participação ativa dos trabalhadores. Ou seja, considerando que o trabalhador, em decorrência de suas dramáticas, do uso do corpo-si, estará no nível mais micro de sua atividade, lidando com questões, confrontos, impasses oriundos das dimensões do polo mercantil, do polo dos valores do bem comum e da própria relação estabelecida com seu trabalho, sendo inviável desconsiderá-las. Até porque, como vimos em Schwartz (1998), a determinação das competências para o trabalho é um exercício necessário e, ao mesmo tempo, uma questão insolúvel, pois mesmo sendo uma questão legítima, a busca de procedimentos ou grades descontextualizadas, codificáveis e homogêneas é incompatível com a pluralidade de registros ou elementos que toda atividade de trabalho tenta articular.

\section{Considerações finais}

Por mais sedutor que seja tentar encontrar soluções para que um serviço público seja considerado de "excelência", esse resultado jamais será alcançado por meio da priorização do serviço privado em detrimento do serviço público. Acreditamos, ao contrário, que é justamente pela incorporação dos valores que norteiam a dimensão do público que caminharemos em direção à conquista de uma sociedade mais justa, com serviços de excelência oferecidos ao cidadão nas áreas da educação, da saúde, da justiça etc.

Ao se falar em educação, em especial a universidade pública, compreendemos que esta necessita de trabalhadores que se coordenem uns aos outros e estejam conectados principalmente a fim de garantir a qualidade do serviço. O trabalhador precisa ser um participante ativo da produção de uma relação de serviço (Zarifian, 
2001c), tendo como finalidade atender às demandas e aos anseios da sociedade brasileira.

Contudo, o cenário anterior só será possível se o trabalhador puder se apropriar de sua atividade. Dito de outra forma, o trabalhador precisa ser convidado a falar sobre a sua situação de trabalho. Mas para que isso aconteça, os gerentes devem estar impregnados do entendimento de que a gestão do trabalho se faz com cada trabalhador, independentemente do nível hierárquico que ele ocupe em uma organização. Acreditamos que somente por meio desse processo, ao dar voz "àquele que age", abriremos caminho para que o ponto de vista da atividade se configure e viabilize dessa maneira a apropriação pelo trabalhador de sua atividade e de todo o sentido que ela comporta.

Trabalhar com o ponto de vista da atividade é difícil, já que envolve dimensões da atividade que nem mesmo o próprio trabalhador toma consciência. É necessário estar ao lado daquele que trabalha, dialogando com ele sobre sua atividade, pois só assim o ponto de vista da atividade será constituído. Somente com essa etapa concluída, ou seja, com um debruçar sobre o que comporta uma atividade de trabalho, é que o debate sobre as competências poderá ser realizado. É necessário atentar para essa questão, pois se não a considerarmos estaremos investindo tempo e energia em processos de gestão por competências que, na realidade, estão alijando os trabalhadores e na verdade são apenas uma modernização do antigo modelo de gerenciamento por postos de trabalho.

Nesse sentido, adotar o ponto de vista da atividade, ou ainda considerar a análise situada de uma situação de trabalho, pode ser um dos caminhos tomados por uma organização para que o debate sobre a gestão por competências - e, consequentemente, sua implementação em dado contexto - ocorra, trazendo resultados favoráveis não apenas à organização, mas também ao trabalhador. Acreditamos, por exemplo, que ao ter como diretriz a perspectiva da atividade, a devida atenção seria dispensada não apenas aos interesses da organização - incluindo o debate sobre os critérios de qualidade, eficácia, eficiência e produtividade de um serviço -, mas também aos interesses do trabalhador, levando-se em conta a dimensão física e mental que o constitui, uma vez que tendo-se por diretriz o ponto de vista da atividade, tais interesses tenderiam a tornar-se inseparáveis e não divergentes.

Concluímos que somente no coletivo do trabalho, ou seja, junto aos trabalhadores, será possível apostar, mesmo eventualmente, na possibilidade de se encontrarem e inventarem maneiras inteligentes e fecundas de se problematizarem as competências para cada um de nós (Schwartz, 2010d). Considerando ainda que "cada um é potencialmente especialista de sua própria experiência, mas o risco é 
de se afirmar como especialista da experiência do outro". (Durrive \& Schwartz, 2001, tradução livre) ${ }^{6}$.

\section{Referências}

Amaral, H. K. (2006). Desenvolvimento de competências de servidores na administração pública brasileira. Revista do Serviço Público, 57(4), 549-563.

Borges, E. S. (2006). O RH está nu: tramas e urdiduras por uma gestão coletiva do trabalho. Tese de doutorado, Curso de Pósgraduação em Psicologia, Universidade do Estado do Rio de Janeiro, Rio de Janeiro.

Brasil (2006). Decreto n. 5.707, de 23 de fevereiro de 2006. Institui a política e as diretrizes para o desenvolvimento de pessoal da administração pública federal direta, autárquica e fundacional, e regulamenta dispositivos da lei n. 8.112, de 11 de dezembro de 1990. Brasília: Presidência da República.

Brasil (2009). A democratização das relações de trabalho: um novo olhar sobre a política de gestão de pessoas da administração pública federal. Brasília: Ministério do Planejamento, Orçamento e Gestão, Secretaria de Recursos Humanos.

Canguilhem, G. (2010). Normal e Patológico. Rio de Janeiro: Forense Universitária.

Duraffourg, J. (2010). O trabalho e o ponto de vista da atividade. In: Y. Schwartz, \& L. Durrive (Orgs.). Trabalho e ergologia: conversas sobre a atividade humana. (pp. 47-82). $2^{\mathrm{a}}$ ed., Niterói: EdUFF.

Durrive, L. \& Y. Schwartz (2001). Vocabulaire (provisoire) de l'Ergologie. Redigido por Louis Durrive e Yves Schwartz. Histoires de Travail - Journal d'un ergonomiste. Disponível em http://www.histoires-de-travail.fr/?q=content/lergologie. Acesso 21 de maio de 2016.

Durrive, L. (2010). As técnicas e a experiência dos humanos. In: Y. Schwartz, \& L. Durrive (Orgs.). Trabalho e ergologia: conversas sobre a atividade humana. (pp. 85-102). 2a ed., Niterói: EdUFF.

Guérin, F., Laville, A., Daniellou, F., Duraffourg, J., \& Kerguelen, A. (2001). Compreender o trabalho para transformá-lo: a prática da ergonomia. São Paulo: Edgar Blucher.

Gomes, P. F. \& Araújo A. J. da S. (2009) A gestão de desempenho por competências no Banco do Brasil: um diálogo entre 0 prescrito e o real da atividade. In: Neves, M. Y., Araújo, A. S., Vieira, S. B. \& Alberto, M. F. P. (Orgs.). Subjetividade e trabalho: "a vida não é só isso que se vê". (pp. 211-231). João Pessoa: Editora UFPB. 
Muniz, H. P. (2000). A gestão do tempo de permanência do paciente de neurocirurgia no Hospital Universitário Clementino Fraga Filho. Tese de Doutorado, Curso de Pós-Graduação em Engenharia de Produção, Universidade Federal do Rio de Janeiro, Rio de Janeiro.

Muniz, H. P., Vidal, M. C., \& Alvarez, D. (2001). Terá a atividade um lugar na avaliação de performance do setor de serviços? Revista Ação Ergonômica, 1(2), 79-91.

Nascimento, B. M. F., \& Muniz, H. P. (2016). Trabajo y subjetividad: contribuciones de la ergología. Poiesis (En Línea), 30, 9-12. http://www.funlam.edu.co/revistas/index.php/poiesis/article/vie w/1859/1484. Acessado em 17 de maio de 2016.

Nogueira, L. C. B. (2012). (Des)envolver pessoas no trabalho: reflexões sobre estratégias de formação e desenvolvimento dos trabalhadores sob o ponto de vista da atividade nas ações em "gestão de pessoas" no serviço público federal. Dissertação de Mestrado, Curso de Pós-Graduação em Psicologia, Universidade Federal Fluminense, Niterói, RJ.

Rezende, M. S. (2014). Atividade de trabalho e desenvolvimento de adultos. Tese de doutorado, Curso de Pós-graduação em Psicologia, Universidade do Estado do Rio de Janeiro, Rio de Janeiro.

Rouilleault, H. (2001). Prefácio. In: F. Guérin, A. Laville, F. Daniellou, J. Duraffourg, \& A. Kerguelen. Compreender o trabalho para transformá-lo: a prática da ergonomia. (pp. XII-XIV). São Paulo: Edgar Blucher.

Schwartz, Y. (1998). Os ingredientes da competência: um exercício necessário para uma questão insolúvel. Revista Educação e Sociedade, 19(65), 101-140.

Schwartz, Y., \& Durrive, L. (Orgs.). Trabalho e Ergologia: conversas sobre a atividade humana. 2a Edição, Niterói, EdUFF, 2010.

Schwartz, Y. (2010a). A linguagem em trabalho. In: Y. Schwartz, \& L. Durrive (Orgs.). Trabalho e ergologia: conversas sobre a atividade humana. (pp. 131-148). 2a ed., Niterói: EdUFF.

Schwartz, Y. (2010b). Técnicas e competências. In: Y. Schwartz, \& L. Durrive (Orgs.). Trabalho e ergologia: conversas sobre a atividade humana. (pp. 85-102). 2a ed., Niterói: EdUFF.

Schwartz, Y. (2010c). Trabalho e uso de si. In: Y. Schwartz, \& L. Durrive (Orgs.). Trabalho e ergologia: conversas sobre a atividade humana. (pp. 189-204). 2a ed., Niterói: EdUFF.

Schwartz, Y. (2010d). Uso de si e competência. In: Y. Schwartz \& L. Durrive (Orgs.). Trabalho e ergologia: conversas sobre a atividade humana. (pp. 205-221). 2a ed., Niterói: EdUFF.

Schwartz, Y. (2010e). O homem, o mercado e a cidade. In: Y. Schwartz, \& L. Durrive (Orgs.). Trabalho e ergologia: conversas 
sobre a atividade humana. (pp. 247-273). $2^{a}$ ed., Niterói: EdUFF.

Schwartz, Y. (2011). Conceituando o trabalho, o visível e o invisível. Revista Trabalho, Educação e Saúde, 9(1), 19-45.

Schwartz, Y. (2014). Motivações do conceito de corpo-si: corpo-si, atividade, experiência. Letras de Hoje, 49(3), 259-274.

Schwartz, Y., \& Mencacci, N. (2008). Trajetória ergológica e a gênese do conceito usos de si. Revista Informática na Educação: teoria e prática, 11(1), 9-13.

Silva-Roosli, A. C. B. (2012). A estratégia saúde da família como produção de serviço: análise do ponto de vista da atividade de trabalho. Tese de doutorado, Curso de Pós-graduação em Psicologia, Universidade do Estado do Rio de Janeiro, Rio de Janeiro.

Souza, W. (2009). Gestão em saúde, uma perspectiva ergológica: com quantos gestos se faz uma gestão. Tese de doutorado, Curso de Pós-graduação em Psicologia, Universidade do Estado do Rio de Janeiro, Rio de Janeiro.

Souza, W. F., \& Christo, C. Souza (2015) Trabalho, vida e gestão: vias para um ergogerenciamento. In: Taveira, I. M. R., Limongi-França, A. C., Ferreira, M. C. (Orgs.). Qualidade de vida no trabalho: estudos e metodologias brasileiras. Curitiba: CRV.

Telles, A. L., \& Alvarez, D. (2004). Interfaces ergonomia-ergologia: uma discussão sobre trabalho prescrito e normas antecedentes. In: M. Figueiredo, M. Athayde, J. Brito, \& D. Alvarez (Orgs.). Labirintos do trabalho: interrogações e olhares sobre o trabalho vivo. (pp. 63-90). Rio de Janeiro: DP\&A.

Zarifian, P. (2001a). Mutação dos sistemas produtivos e competências profissionais: a produção industrial de serviço. In: M. S. Salerno (Org.). Relação de serviço: produção e avaliação. (pp. 69-93). São Paulo: Senac.

Zarifian, P. (2001b). Objetivo competência: por uma nova lógica. São Paulo: Atlas.

Zarifian, P. (2001c). Valor, organização e competência na produção de serviço: esboço de um modelo de produção de serviço. In: M. S. Salerno (Org.). Relação de serviço: produção e avaliação. (pp. 95-149). São Paulo: Senac.

Zarifian, P. (2003). O modelo da competência: trajetória histórica, desafios atuais e proposta. São Paulo: Senac.

\section{Endereço para correspondência \\ Claudete Francisco de Sousa}

Universidade Federal Fluminense - UFF

Progepe - SPSF - $1^{\circ}$ Andar - Reitoria

Avenida Miguel de Frias, 09, Icarai, CEP 24220-900, Niterói - RJ, Brasil

Endereço eletrônico: claudetesousa57@gmail.com 


\section{Hélder Pordeus Muniz}

Universidade Federal Fluminense - UFF

Rua Prof. Waldemar de Freitas Reis, s/n, bloco N, Campus Gragoatá, CEP 24210201, Niterói - RJ, Brasil

Endereço eletrônico: heldermuniz@uol.com.br

Recebido em: 30/05/2016

Reformulado em: $13 / 07 / 2016$

Aceito em: 22/10/2016

\section{Notas}

* Psicóloga da Universidade Federal Fluminense. Doutoranda do Programa de Pós Graduação em Psicologia da UFF. Participante do Grupo de Pesquisa Gestão, Trabalho e Atividade - GESTA.

** Professor do Departamento e da Pós-graduação em Psicologia da UFF. Coordenador do Grupo de Pesquisa Gestão, Trabalho e Atividade - GESTA.

${ }^{1}$ Considerando a perspectiva teórica que norteia este estudo, defendemos a ideia de uma "gestão que se realiza com pessoas", pois, a gestão será sempre coletiva e plural e, a atividade de trabalho caracterizada por uma dimensão gestionária, em que, o trabalhador, gestará cada dia de seu trabalho de maneira singular, a fim de dar conta das variabilidades presentes no meio.

2 Esta é uma concepção, oriunda da filosofia da vida de Georges Canguilhem, utilizada por Schwartz (2010b), que a aplica aos meios ou ambientes técnicos, dispondo que o meio é sempre infiel, visto que jamais se repete de um dia para o outro, ou em uma situação de trabalho para a outra. E, para lidar com tais infidelidades, o ser humano deverá geri-las através de suas próprias capacidades, de seus próprios recursos e de suas próprias escolhas, fazendo um "uso de si", a propósito da tendência de cada um sempre renormatizar seu meio de vida e seu meio de trabalho. Assim, gerir as infidelidades do meio significa "viver" já que, ao ser vivo, não é possível estar submetido unicamente ao registro das normas, de imposições, de regras, e de execução de instruções, pois isso seria patológico (Canguilhem, 2010). A vida, nesse sentido, se apresentaria sempre como uma tentativa de criar-se parcialmente.

3 Atualmente, somam-se aos dispositivos de pesquisa tradicionais (observação direta, indireta, questionários, entrevistas, etc) outros mais, com o fim de se alcançar o ponto de vista da atividade. Podemos citar a auto-confrontação cruzada e a instrução ao sósia. A esse respeito, Rouilleault (2001, p.XIV) afirma que, se não existe um bom modelo, bons métodos existem, sobretudo para uma confrontação com múltiplos critérios de visões e para uma valorização da atividade de trabalho.

${ }^{4}$ O serviço é oferecido pela chamada Seção de Prevenção Sócio Funcional (SPSF), um espaço voltado para os servidores no qual, por meio de uma equipe formada por assistentes sociais e psicólogos, alguns projetos são desenvolvidos tendo como objetivo orientar e acompanhar o servidor acerca de questões que possam trazer dificuldades e prejuízos para o seu bem-estar físico, psíquico e social na organização.

5 De acordo com Muniz, Vidal e Alvarez (2001), classificá-los como valores "sem dimensão" não significa que eles devem ser considerados como absolutos, transcendentes e considerados como ideias reguladoras das conjunturas onde vão operar, mas sim que eles devem sempre funcionar em princípios de ação.

6 Trecho original extraído do Vocabulário provisório de Ergologia. Significado de Expert: "Chacun est potentiellement expert de sa propre expérience, mais le risque est de se prétendre expert de l'expérience d'autrui". 